Int. J. Dev. Biol. 53: 1563-1568 (2009)

doi: $10.1387 / \mathrm{ijdb} .093021 \mathrm{ad}$

\title{
Reprogramming of melanoma cells by embryonic microenvironments
}

\author{
ALEJANDRO DÍEZ-TORRE, RICARDO ANDRADE, CRISTINA EGUIZÁBAL, ELIXABETE LÓPEZ, \\ JON ARLUZEA, MARGARITA SILIÓ and JUAN ARÉCHAGA* \\ Laboratory of Stem Cells, Development and Cancer. Department of Cell Biology and Histology and \\ Analytical and High Resolution Biomedical Microscopy Core Facility, University of the Basque Country, \\ Leioa, Vizcaya, Spain
}

\begin{abstract}
In recent years, the reversion of the cancer phenotype of human melanoma cells in developing zebrafish and chick embryos has been reported. The aim of this review is to revise these and other related contributions regarding the regulation of embryonic cancer and to provide a framework with which to understand results from our laboratory on the interactions of human melanoma cells with post-implanted mouse embryos cultured in vitro. To this end, we used the A375 human melanoma cell line transfected with the green fluorescent protein (GFP) gene. Labeled cells were transplanted onto the surface of the developing visceral endoderm of $7.5 \mathrm{dpc}$ mouse embryos. Subsequently, we cultured the transplanted embryos for three days and monitored the movements of GFP labeled human melanoma cells by confocal microscopy. Our results show that ectopic melanoma cells internalize and migrate inside the embryo body in a way reminiscent of neural crest cells. The absence of localized tumor growth after 72 hours of in vitro embryo co-culture suggests that malignant phenotype inhibiting factors are active at the gastrulating stage and during early organogenesis. These results complement previous reports of growth regulation of B16 mouse melanoma cells by 10 dpc mouse embryonic skin (Gerschenson et al., 1986). Further research is required to elucidate the final fate of melanoma cells in mammalian embryos and the details of the signaling pathways underlying tumor growth regulation. Understanding the regulation of melanoma cells by young embryos could represent a starting point for a developmental theory of the pathogenesis of melanoma, and for future developments of more physiologically-based anticancer therapies for this and indeed, other types of aggressive tumor.
\end{abstract}

KEYWORDS: cancer stem cell, cancer microenvironment, melanoma reprogramming, melanoma regulation, embryonic control of cancer, stem cell reprogramming

In the last decades, our knowledge about tumor pathogenesis has been growing in a constant manner. Even though many oncogenes and tumor suppressor genes have been identified, it is broadly accepted that they are not enough for governing tumor behavior and that the crosstalk between tumor cells and their microenvironment plays a critical role in cancer progression. Indeed, many studies have demonstrated that the malignant phenotype can be reverted by changes in the environmental conditions without altering the tumor cell genotype (Brinster, 1974; Postovit et al., 2007). The epigenetic reprogramming of malignant cells by embryonic environments has been suggested to be due to common regulatory signals shared by embryonic and tumor stem cells (Abbott et al., 2008). Supporting this proposal, several factors, including members of the Wingless (Wnt), Notch and Transforming Growth Factor Beta (TGF-beta) superfamilies, have been recently identified as common molecular messengers involved in the interaction of both malignant tumor cells and embryonic stem cells with their respective microenvironment, suggesting a convergence of embryonic and cancer stem cell signaling pathways (Topczewska et al., 2006; Balint et al., 2005; Dissanayake et al., 2007).

The experimental demonstration of cancer stem cell differentiation in some kind of tumors by Barry Pierce and co-workers and his theory of cancer cells as a "caricature" of the normal process of tissue renewal was an important advance in the understanding of cancer biology (Aréchaga, 1993). They also demonstrated the

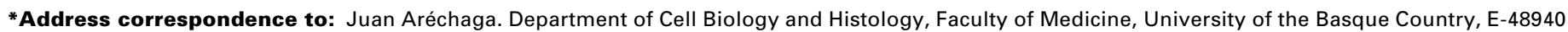
Leioa, Vizcaya, Spain. Fax: +34-946-013-266. e-mail: juan.arechaga@ehu.es

Final author-corrected PDF published online: 5 November 2009.
}

ISSN: Online 1696-3547, Print 0214-6282 
pluripotency of single undifferentiated embryonal carcinoma cells (EC cells) engrafted in an adult syngenic mouse. Such cells are able to produce a teratocarcinoma containing different celllineages derived from the three germ layers (Kleinsmith and Pierce 1964). This was really the first experiment that showed a similarity between the biological behavior of cancer and embryonic stem cells (ES cells). The next step up in establishing the convergence in signaling pathways regulating tumor and embryonic stem cell plasticity was taken by Ralph Brinster when he demonstrated that murine blastocysts injected with EC cells can give rise to healthy chimeric mice (Aréchaga, 1998). The absence of tumors in some of the resulting adult chimeras proved the ability of the embryonic microenvironment to abrogate the metastatic phenotype of malignant tumor cells. Brinster evidenced the presence of EC cell derived tissues in the chimeric mice by using mouse strains with different skin pigmentation. Mintz and IIImensee (1975) went further in their observations and demonstrated that EC cells injected into the blastocyst take part in the development of tissues derived from the three germ layers and even colonized the germ line, in agreement with the EC cell plasticity previously described by Pierce's group (Aréchaga, 1993). A decade after these great pioneer assays, supplemental experiments added new evidences supporting the tumor-suppressing ability of the embryonic microenvironment, not only in the mouse but also in other animal models, such as the chick embryo. Dolberg and Bissell (1984), for example, showed that the Rous sarcoma virus (which rapidly transform chick adult cells in vivoand chick embryo derived fibroblast in vitro) is non-tumorigenic when 4 days chicken embryos are infected, even though the virus does replicate in the embryo cells. Moreover, when infected embryo tissues are dissected and their cells are maintained in vitro, they manifest a transformed phenotype after just 24 hours of culture. Pierce and colleagues (1982) threw new light on this issue when observed that only those carcinomas with a normal embryonic counterpart are regulated by the blastocyst and that the malignant phenotype abrogation of carcinoma cells takes place just in their closely related embryonic fields (Aréchaga 1993). Supporting these observations, Pierce and co-workers (Gerschenson et al., 1986) specifically showed that the incidence of tumors derived from B16 Murine melanoma cells transplanted under the skin of $10 \mathrm{dpc}$ mouse embryos (at the time of the arrival of migrating premelanocytes) was significantly reduced. These in vivo observations were further confirmed in vitro using embryonic skin conditioned medium to see its effect on B16 melanoma cell colony formation efficiency. Moreover, after the exposure to embryonic skin derived factors, the melanoma B16 cell line reduced considerably its ability to form tumors in vivo.

\section{Human melanoma regulation by the zebrafish embryo}

Zebrafish embryo model has been used to study the crosstalk between tumor cells and the embryonic environment in order to clarify which signaling pathways involved in embryonic development also participates in the maintenance of tumor cell plasticity. With this aim, Lee et al. (2005) transplanted human melanocytes and metastatic melanoma cells into zebrafish blastula-stage embryos and monitored their behavior after transplantation. Both melanocytes and melanoma cells were able to survive, divide and migrate into the developing embryo without forming tumors. The maintenance of the dedifferentiated state of melanoma cells was reflected by the random and scattered distribution of the tumor cells into the interstitial spaces of the embryo whereas the melanocytes were prone to localize in the skin, suggesting that they were responding to homing signals that direct them to their normal fate in the embryo. The melanoma cells injected into the blastula-stage embryos lost their tumorigenic phenotype and could be observed in the adult animals for a period of at least 3 months without forming tumors. Furthermore, cells from other kind of tumors, like human colon cancer, have been shown to undergo proliferation rate reduction and apoptosis when treated with zebrafish embryo-derived extracts (Cucina et al., 2006). Interestingly enough, it has been communicated that melanoma cells transplanted into the zebrafish embryo when the organogenesis is complete are not reprogrammable, give rise tumors and induce angiogenesis (Haldi etal., 2006). These results show that the ability of the embryo microenvironment to reprogramming malignant tumor cells is significantly reduced after organogenesis.

A different set of experiments with zebrafish embryos and melanoma cells demonstrated that the ability of tumor cells to interact with the developing embryo is linked to their aggressive and plastic phenotype. Invasive melanoma cells, but not the poorly aggressive ones, lead to the formation of an abnormal anterior appendage when transplanted into the animal pole and produce a duplication of the body axis when placed near the yolk margin. In all these processes, melanoma cell activity is limited to the organization of the host zebrafish cells without directly inducing abnormal out-
Fig. 1. Initial and final embryonic stage of our observations. (A) Schematic drawing of the initial position of labeled human melanoma cells (in green) on the surface of the visceral endoderm of a $\sim 7.5 \mathrm{dpc}$ mouse embryo. Reichert's membrane had to be removed in order to allow the embryo

to grow in culture. (B) Mouse embryo of $\sim 10.5 \mathrm{dpc}$ after 3 days of in vitro culture.
B

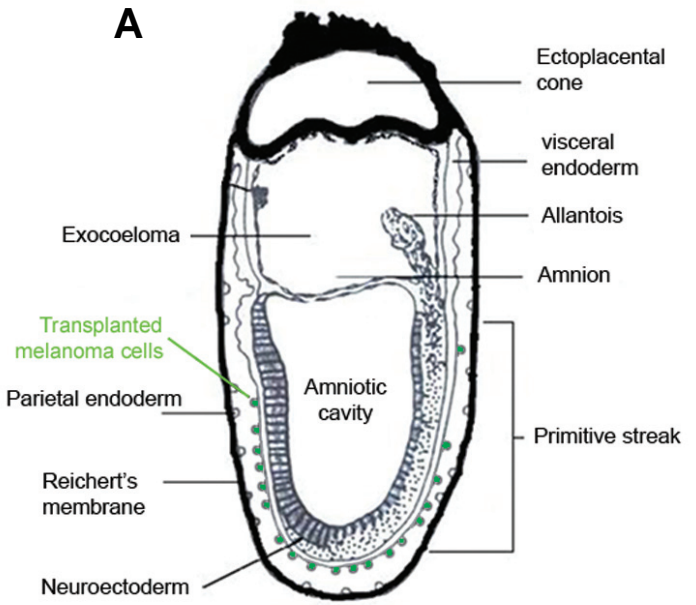



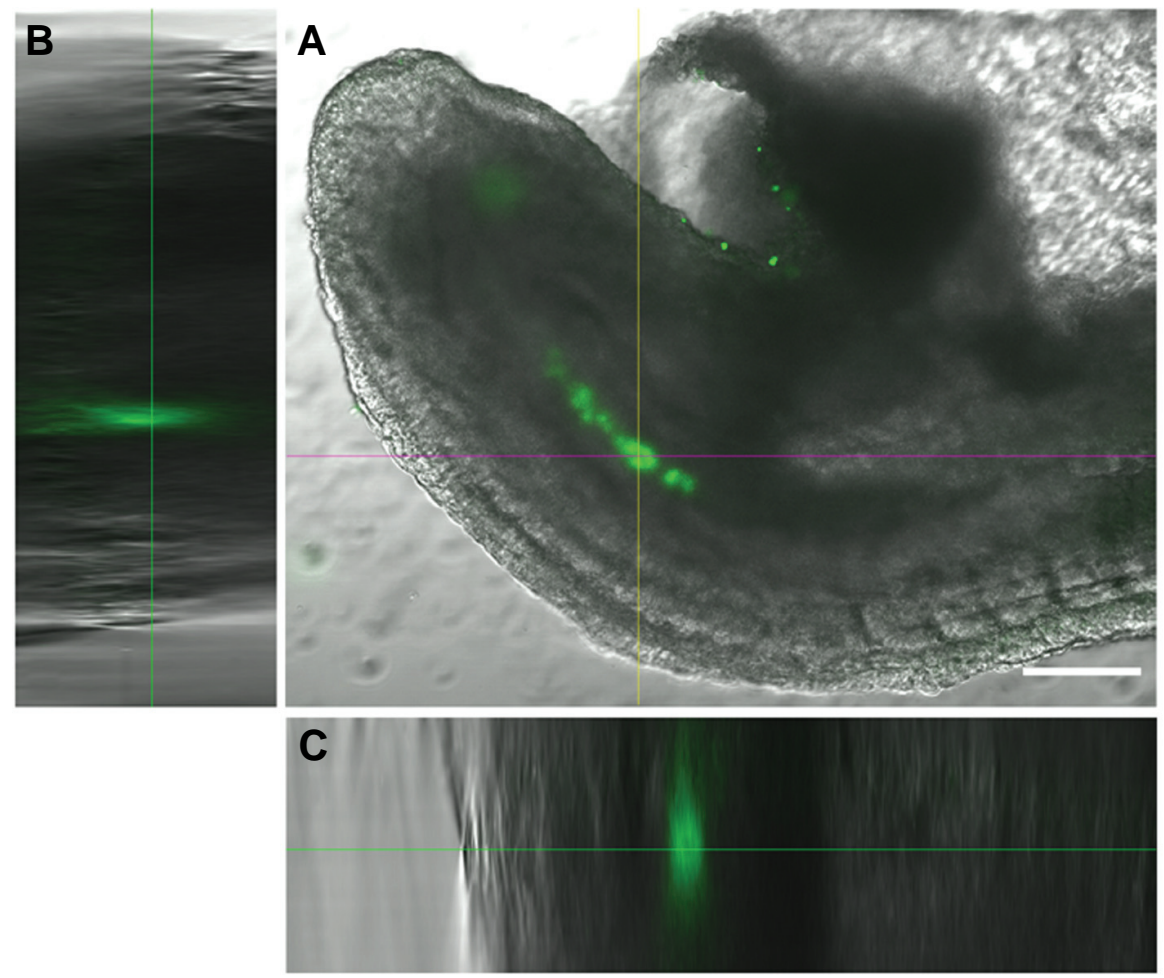

that migrates from the neural tube and invades throughout the embryo body during vertebrate development. Neural crest cell to melanoblast transition involves the restriction of pluripotent cell plasticity in order to determine the melanogenic lineage and finally the melanocyte phenotype. Wnt and BMP signaling pathways mainly govern this specification process. The melanocyte fate determination is also directed by the transcriptional repressor FoxD3, repressor of melanogenesis in premigratory NC cells and in other NC lineages (Thomas and Erickson 2009). The fate of each migratory neural crest cell seems to be determined by a combination of signals produced by the neural tube itself and the microenvironment along the migratory route (Lumsden et al., 1991; Trainor and Krumlauf 2000).

It has been observed that chick embryo microenvironment abrogate the malignant melanoma cell phenotype, since melanoma cells transplanted to it does not form tumors and some of them acquires neural crest celllike phenotype, migrating into neural crest normal targets, such as branchial arches, dorsal root or sympathetic ganglia (Kulesa et al., 2006). Some of the transplanted melanoma cells that invaded the embryonic periphery responded to developmental signals from the embryo and expressed the melanocyte marker Fing 2 . A375-GFP-Np human melanoma cells internalized into the central axis of caudal region of the mouse embryo. (A) Merge of green fluorescence and transmitted light channels obtained by confocal microscopy. (B,C) Orthogonal views of a $200 \mu \mathrm{m}$ Z-stack showing the internal location of the fluorescent labeled melanoma cells. Bar, $100 \mu \mathrm{m}$

growths of the embryo (Topczewska et al., 2006). Subsequent experiments demonstrated that the ability of melanoma stem cells to direct the embryonic development is due to the secretion of Nodal, a potent morphogen of the TGF-beta superfamily (Schier, 2003). Knowing that Nodal is highly secreted by aggressive melanoma cells but it is not detected in normal skin or non-invasive melanoma cells, and having seen its effects on embryonic developments, it seems to be involved in both embryonic and tumorigenic signaling pathway. Additional experiments have confirmed this observation. The expression of Goosecoid, a Nodal-responsive gene, was shown to be upregulated in zebrafish cells surrounding the implanted melanoma cells one hour after transplantation. On the other hand, it has been proven that the formation of melanoma cells mediated ectopic outgrowths in the zebrafish embryo is totally disrupted by the inhibition of Noda/expression with specific morpholinos or by the abrogation of its activity by inhibiting its downstream mediator activin-like kinase (Topczewska et al., 2006).

\section{Reprogramming of human melanoma cells by the chick embryo}

Due to the common migratory and invasive properties shared by neural crest cells and malignant melanoma cells, the chick embryo model has been especially useful in the study of the neural crest regions to reprogramming human metastatic melanoma phenotype. Melanocytes differentiate from the neural crest (NC), which is constituted by a multipotent cell population
MLANA and the neuronal marker TUJ1, suggesting a transition from malignant melanoma to benign melanocytic phenotype.

\section{The mammalian embryo approach to study the embry- onic control of cancer cells}

As mentioned before, the pioneer experiments demonstrating the ability of embryonic microenvironment to revert tumor malignant phenotype were carried out by Brinster and Pierce groups, using the mouse blastocysts as a model system (Aréchaga 1993, 1998). Pierce and co-workers also explored cancer growth regulation by their related mouse embryonic fields during organogenesis after several in vitro approaches (Pierce et al., 1986). Nevertheless, as we have seen, recent progress in this issue have substituted the mouse embryos for alternative animal models whose whole development can be easily followed in vitro, such as zebrafish or chick embryos. But, even though these models offer many advantages for longer observations of tumor cell behavior into the embryo and adult animals, it is advisable to compare the results obtained in such models with those obtained in mammalian embryos, which are presumably more closely related to the environment found in the human embryos. Following this approach, Hochedlinger et al. (2004) have been able to reprogram RAS-inducible melanoma cells by activated mouse oocytes after nuclear transfer, obtaining normally developed embryos that reach the blastocyst stage and derived pluripotent ES cells lines. Later, Astigiano and colleagues (2005) have recently recovered the use of the mouse model in order to clarify 
for how long the embryonic environment shows the ability to abolish the malignant phenotype. With this purpose, several EC cell lines were injected in intrauterine post-implantation mouse embryos at different developmental stages, from E8.5 embryos to newborn and adult mice. The transplanted cell viability, migration and tumor formation ability were then monitored and it was observed that the percentage of animals that develop tumors increases with the age of the embryo at the moment of the carcinoma cell transplantation. These assays confirm that the ability to abrogate malignancy by the embryonic environment is gradually reduced as the development progresses and, eventually, it is completely lost after the organogenesis stage.

However, the previously mentioned experiments on the reversion of the cancer phenotype by mammalian embryos present some disadvantages. Thus, observations are not currently possible beyond the blastocyst stage; however, live chimeras with derived ES cell lines have been obtained. These lines were previously cultured for some passages in vitro, and the resulting animals do develop tumors (Hochedlinger et al., 2004). Other inconveniences include the difficulty of injecting cells in uterointo specific places (Gerschenson et al., 1986; Astigiano et al., 2005). Here we present a new approach using post-implanted mouse embryos cultured in vitro to analyze the ability of the embryonic microenvironment to regulate melanoma cell malignant behavior during organogenesis.

Our experiments are based on the culture system developed by Denis New (Aréchaga, 1997) that allows the culture of postimplantation mouse embryos for some days. Briefly, A375 human melanoma cells expressing the fusion protein Green Fluorescent Protein-Nucleoplasmin (GFP-Np) into their nucleus were attach to the surface of the visceral endoderm of gastrulating mouse embryos in order to observe their interactions and to localize their position after three days of culture (Fig. 1). The observations by confocal microscopy showed that melanoma cells were located mainly in the caudal region of the embryo, and in most of the cases they have been able to migrate and appear internalized in the embryo tissues. The distribution of the GFP labeled melanoma
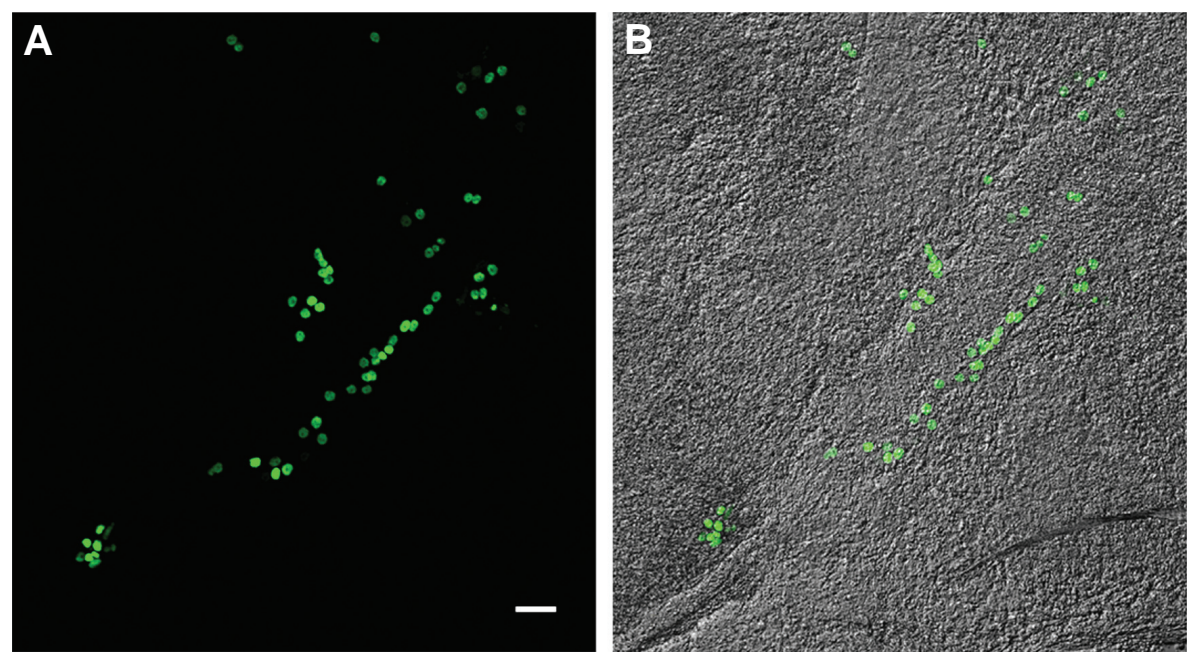

Fig. 3. Squash preparation of a mouse post-implanted embryo colonized by A375-GFP-Np human melanoma cells after $\mathbf{3}$ days of co-culture. Human melanoma cells seem to migrate along the body axis. (A) Green fluorescence channel. (B) Merge of green fluorescence and transmitted light channels. Bar, $50 \mu \mathrm{m}$. cells forming a row along the midline of the embryo body also suggests that they migrate in an orderly manner in response to some migratory cues (Figs. 2 and 3). Tumor formation was not detected in any of the analyzed embryos.

These observations with human melanoma cells support previous works that suggested the reprogramming of mouse melanoma genome by the embryonic microenvironments during early embryogenesis and organogenesis (Gerschenson et al., 1986; Hochedlinger et al., 2004). Our results with cultured post-implanted mouse embryos confirm also those obtained recently with zebrafish and chick embryos (Lee et al., 2005; Kulesa et al., 2006), what points out the universality of the mechanisms involved in cancer cell reprogramming by embryonic microenvironment.

\section{Discussion and perspectives}

An increasing number of studies support the idea that some characteristics shared by embryonic and cancer stem cells, such as plasticity and undifferentiated phenotype, are regulated, at least partially, by common mechanisms. Similarities between both cell types are corroborated by the current cancer stem cell theory, which postulates that the origin of several types of cancer lay on tumor stem cell niches (Pierce, 1983). Over the past few years, several assays have demonstrated the reversion of the metastatic phenotype of human melanoma cells by the embryonic microenvironment using zebrafish and chick embryos as models (Lee et al., 2005; Kulesa et al., 2006) but the use of a postimplanted mammalian experimental model could provide better conditions and cues closer to those found in the human microenvironments. In our experiments, the absence of localized tumoral growth after 72 hours of embryo co-culture with metastatic melanoma cells confirm that malignant phenotype inhibiting factors are active at the gastrula stage and early organogenesis. Although further research is needed to elucidate the specific fate of transplanted melanoma cells and the signaling pathways involved in cancer inhibitory mechanisms of the mammalian embryo, the present approach confirm the presence of cancer regulatory mechanisms in the mammalian embryos cultured in vitro. A good starting point to understand the main molecular changes underlying the pathogenesis of this aggressive tumor (Palmieri et al., 2009) from the development point of view and for future progresses to the development of biological based anticancer therapies.

\section{Materials and Methods}

\section{Mouse embryos}

$7.5 \mathrm{dpc}$ mouse embryos were obtained from OF1 random bread albino Swiss strain (Crifa, France) following the method developed by New (1978). According to it, the uterine horns containing embryos were extracted into Petri dishes with PBS solution and uterine walls were ripped and discarded to uncover the decidua mass surrounding the egg cylinder stage embryos. The decidua swelling was transfer to a new dish with fresh PBS solution and then dissected carefully into two halves 
to obtain the embryos. After, the Reichert's membrane of collected embryos was tore and they were transferred to $2 \mathrm{ml}$ of pre-equilibrated culture medium in $30 \mathrm{ml}$ tubes (two embryos per tube).

\section{A375 human melanoma cells expressing GFP-Np fusion protein}

A375 human melanoma cells were obtained from American Type Culture Collection (ATCC, Ref. CRL-1619). Cells were cultured in Dulbecco's modified Eagle's Medium (DMEM) supplemented with 10\% fetal calf serum (FCS) and $1 \%$ penicillin/streptomycin at $37^{\circ} \mathrm{C}$ in $5 \% \mathrm{CO} 2$. To yield the vector pGFP-Np, we employed a full length nucleoplasmin cDNA sequence was obtained by PCR from pET-11b using N-term (CAGTAGATCTATGGCCTCTACCGTCAGCAA) and C-term (TTAAGAATTCTCACTTCTTAGCAGCCGGCTT) primers. The amplified fragment was digested with Bglll and EcoR1 restriction enzymes, respectively (underlined) and ligated to eGFP-C1 (Clontech). Competent Escherichia coli (JM 109 strain) were transformed and the plasmid was isolated and verified by sequencing. $1 \times 104$ A375 melanoma cells per well were cultured overnight in 24 well plates. Afterwards, cells were transfected with pGFP-NP using FUGENE 6 (Roche) according to the manufacturer instructions. Stable A375 GFP-Np cell lines were generated by clonal selection. Maintenance of the culture was performed adding the $\mathrm{G}$ 418 antibiotic to the growth medium (Andrade et al., 2009).

\section{Whole-embryo culture conditions}

Rats of the Sprague Dawley strain were used to extract blood from the dorsal artery. The blood was immediately centrifuged at $4^{\circ} \mathrm{C}$ and the obtained serum was decomplemented by means of incubation at $56^{\circ} \mathrm{C}$ during 30 minutes. The resulting serum was used to prepare the culture medium ( $50 \%$ rat serum in DMEM). The culture of the embryos was carried out in tubes of $30 \mathrm{ml}$ at $37^{\circ} \mathrm{C}$ in a rotatory system at $35 \mathrm{rev} / \mathrm{min}$ with a constant flow of gas. Oxygen tension in the gas was gradually increased, being $5 \%$ during the first 24 hours, $20 \%$ during the next 24 hours and $40 \%$ during the last 24 hours. A375 human melanoma cells expressing GFP-Np fusion protein were added to the culture medium at a density of 500.000 cells per $\mathrm{ml}$

\section{Confocal microscopic observations}

Embryos co-cultured with fluorescent labeled human melanoma cells were observed by with a Fluoview FV500 Olympus confocal microscope after 72 hours of culture.

\section{Acknowledgements}

This work was supported by a research project from the Spanish Ministry of Education and Science (BFU 2007-66610) and a Research Group Grant (GIU08/04) from the University of the Basque Country to J.A.; A.D-T. and E.L. had fellowships from the Jesús Gangoiti Barrera Foundation of Bilbao, Spain.

\section{References}

ABBOTT D E, BAILEY C M, POSTOVIT L M, SEFTOR E A, MARGARYAN N, SEFTOR R E, HENDRIX M J (2008) The Epigenetic Influence of Tumor and Embryonic Microenvironments: How Different are They? Cancer Microenviron 1:13-21.

ANDRADE R, CRISOL L, PRADO R, BOYANO MD, ARLUZEA J and ARÉCHAGA J. (2010). Plasma membrane and nuclear envelope integrity during the blebbing stage of apoptosis: a time-lapse study. Bio/ Cell. 102: 25-35.

ARÉCHAGA J (1993) On the boundary between development and neoplasia. An interview with G Barry Pierce. Int J Dev Bio/37: 5-16.

ARÉCHAGA J (1997) Technique as the basis of experiment in developmental biology. An interview with Denis A T New. Int J Dev Bio/41: 139-152.

ARÉCHAGA J (1998) Embryo culture, stem cells and experimental modification of the embryonic genome. An interview with Ralph L. Brinster. Int J Dev Bio/42: $861-878$
ASTIGIANO, S., DAMONTE, P., FOSSATI, S., BONI, L. AND BARBIERI, O. (2005) Fate of embryonal carcinoma cells injected into postimplantation mouse embryos. Differentiation 73: 484-490

BALINT K, XIAO M, PINNIX C C, SOMA A, VERES I, JUHASZ I, BROWN E J, CAPOBIANCO A J, HERLYN M, LIU Z J (2005) Activation of Notch1 signaling is required for beta-catenin-mediated human primary melanoma progression. $J$ Clin Invest 115: 3166-3176.

BRINSTER R L (1974) The effect of cells transferred into the mouse blastocyst on subsequent development. J Exp Med140: 1049-1056.

CUCINA A, BIAVA P M, D'ANSELMI F, COLUCCIA P, CONTI F, DI CLEMENTE R, MICCHELI A, FRATI L, GULINO A, BIZZARRI M (2006) Zebrafish embryo proteins induce apoptosis in human colon cancer cells (Caco2). Apoptosis 11: 1617-28.

DISSANAYAKE S K, WADE M, JOHNSON C E, O'CONNELL M P, LEOTLELA P D, FRENCH A D, SHAH K V, HEWITT K J, ROSENTHAL D T, INDIG F E, JIANG Y, NICKOLOFF B J, TAUB D D, TRENT J M, MOON R T, BITTNER M, WEERARATNA A T (2007) The Wnt5A/protein kinase $C$ pathway mediates motility in melanoma cells via the inhibition of metastasis suppressors and initiation of an epithelial to mesenchymal transition. J Biol Chem. 282: 1725971.

DOLBERG D S, BISSELL M J (1984) Inability of Rous sarcoma virus to cause sarcomas in the avian embryo. Nature 309: 552-556.

GERSCHENSON M, GRAVES K, CARSON S D, WELLS R S AND PIERCE G B (1986) Regulation of melanoma by the embryonic skin. Proc Nat/ Acad Sci USA 83: 7307-7310.

HALDI M, TON C, SENG W L, MCGRATH P (2006) Human melanoma cells transplanted into zebrafish proliferate, migrate, produce melanin, form masses and stimulate angiogenesis in zebrafish. Angiogenesis 9: 139-51.

HOCHEDLINGER K, BLELLOCH R, BRENNAN C, YAMADA Y, KIM M, CHIN L, JAENISCH R (2004) Reprogramming of a melanoma genome by nuclear transplantation. Genes \& Development 18: 1875-1885.

KLEINSMITH L J, PIERCE G B (1964) Multipotentiality of single embryonal carcinoma cells. Cancer Res 24: 1544-1552.

KULESA P M, KASEMEIER-KULESA J C, TEDDY J M, MARGARYAN N V, SEFTOR E A, SEFTOR R E B, HENDRIX M J (2006) Reprogramming metastatic melanoma cells to assume a neural crest cell-like phenotype in an embryonic microenvironment. Proc Nat/ Acad Sci USA 103:3752-3757.

LEE L M, SEFTOR E A, BONDE G, CORNELL R A, HENDRIX M J (2005) The fate of human malignant melanoma cells transplanted into zebrafish embryos: assessment of migration and cell division in the absence of tumor formation. Dev Dyn 233: 1560-70.

LUMSDEN A, SPRAWSON N, GRAHAM A (1991) Segmental origin and migration of neural crest cells in the hindbrain region of the chick embryo. Development 113: 1281-1291.

MINTZ B, ILLMENSEE K (1975) Normal genetically mosaic mice produced from malignant teratocarcinoma cells. Proc Nat/ Acad Sci USA 72: 3585-3589.

NEW D A T (1978) Whole-embryo culture and the study of mammalian embryos during organogenesis. Biol Rev 53: 81-122.

PALMIERI G, CAPONE M E, ASCIERTO M L, GENTILCORE G, STRONCEK D F, CASULA M, SINI M C, PALLA M, MOZZILLO N, ASCIERTO P A (2009). Main roads to melanoma. J Tras/ Med7 (doi: 10.1186/1479-5876-7-86).

PIERCE G B (1983) The cancer cell and its control by the embryo. Am J Path 113 117-124.

PIERCE, G. B., PANTAZIS, C. G., CALDWELL, J. E. AND WELLS, R. S. (1982) Specificity of the control of tumor formation by the blastocyst. Cancer Res 42 : 1082-1087.

PIERCE G B, ARÉCHAGA J, WELLS R S (1986) Embryonic control of cancer. In Cellular Endocrinology: Hormonal Control of Embryonic and Cellular Differen tiation (Eds. G Serrero and J Hayashi) pp 67-77.

POSTOVIT L M, COSTA F F, BISCHOF J M, SEFTOR E A, WEN B, SEFTOR R B, FEINBERG A P, SOARES M B, HENDRIX M J (2007). The commonality of plasticity underlying multipotent tumor cells and embryonic stem cells. J Cell Biochem 101: 908-917.

SCHIER A F (2003) Nodal signalling in vertebrate development. Annu Rev Cel/ Dev 
Biol 19: 589-621.

THOMAS A J, ERICKSON C A (2009) FOXD3 regulates the lineage switch between neural crest-derived glial cells and pigment cells by repressing MITF through a non-canonical mechanism. Development 136: 1849-1858.

TOPCZEWSKA J M, POSTOVIT L M, MARGARYAN N V, SAM A, HESS A R,
WHEATON W W, NICKOLOFF B J, TOPCZEWSKI J, HENDRIX M J (2006) Embryonic and tumorigenic pathways converge via Nodal signaling: role in melanoma aggressiveness. Nature Med12: 925-932.

TRAINOR P, KRUMLAUF R (2000) Plasticity in mouse neural crest cells reveals a new patterning role for cranial mesoderm. Nature Cel/ Bio/2:96-102.

\section{Further Related Reading, published previously in the Int. J. Dev. Biol.}

See our recent Special Issue Epigenetics \& Development edited by Saadi Khochbin and Stefan Nonchev at: http://www.ijdb.ehu.es/web/contents.php?vol=53\&issue=2-3

The hidden maternal-fetal interface: events involving the lymphoid organs in maternal-fetal tolerance Elizabeth S. Taglauer, Kristina M. Adams Waldorf and Margaret G. Petroff Int. J. Dev. Biol. in press (doi: 10.1387/ijdb.082800et)

Modeling and quantification of cancer cell invasion through collagen type I matrices Olivier De Wever, An Hendrix, Astrid De Boeck, Wendy Westbroek,Geert Braems, Shahin Emami, Michèle Sabbah, Christian Gespach, Marc Bracke Int. J. Dev. Biol. in press (doi: 10.1387/ijdb.092948ow)

Using fruitflies to help understand the molecular mechanisms of human hereditary diffuse gastric cancer

Joana Caldeira, Paulo S. Pereira, Gianpaolo Suriano and Fernando Casares Int. J. Dev. Biol. (2009): 53: 1557-1561. (doi: 10.1387/ijdb.072277jc)

Genome reprogramming during sporulation

Jerome Govin and Shelley L. Berger

Int. J. Dev. Biol. (2009) 53: 425-432

Placental metabolic reprogramming: do changes in the mix of energy-generating substrates modulate fetal growth?

Nicholas P. Illsley, Isabella Caniggia and Stacy Zamudio

Int. J. Dev. Biol. in press (doi: 10.1387/ijdb.082798ni)

Genetic and epigenetic instability of human bone marrow mesenchymal stem cells expanded in autologous serum or fetal bovine serum

John-Arne Dahl, Shivali Duggal, Neralie Coulston, Douglas Millar, John Melki, Aboulghassem Shahdadfar, Jan E. Brinchmann and Philippe Collas

Int. J. Dev. Biol. (2008) 52: 1033-1042

Pluripotency and differentiation in embryos and stem cells - Pavia, 17-18 January 2008 James A. Adjaye, Anne G. Byskov, Jose B. Cibelli, Ruggero De Maria, Stephen Minger, Maurilio Sampaolesi, Giuseppe Testa, Catherine Verfaillie, Magdalena Zernicka-Goetz, Hans Schöler, Michele Boiani, Nicola Crosetto and Carlo A. Redi Int. J. Dev. Biol. (2008) 52: 801-809

Human conjunctival epithelial precursor cells and their progeny in 3D organotypic culture Alfredo Rosellini, Sandra Papini, Claudio Giannarini, Marco Nardi and Roberto P. Revoltella Int. J. Dev. Biol. (2007) 51: 739-743

Epigenetic reprogramming of the genome--from the germ line to the embryo and back again

K L Arney, S Erhardt, R A Drewell and M A Surani

Int. J. Dev. Biol. (2001) 45: 533-540

Growth factors and proto-oncogenes in early mouse embryogenesis and tumorigenesis K Pavelic, N P Slaus and R Spaventi Int. J. Dev. Biol. (1991) 35: 209-214

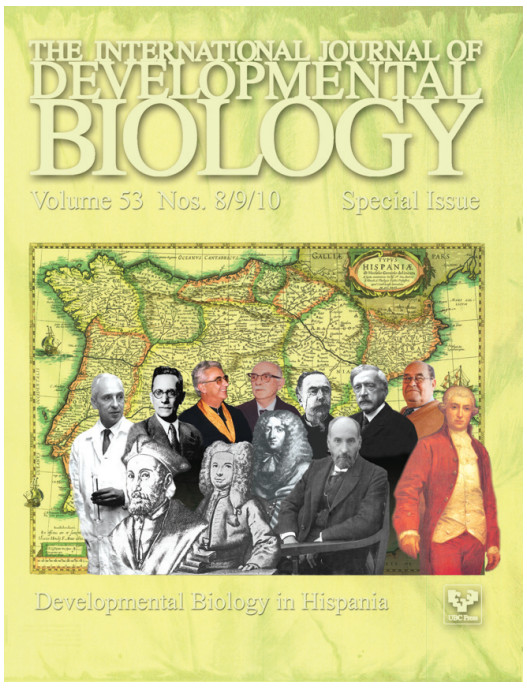

5 yr ISI Impact Factor $(2008)=3.271$

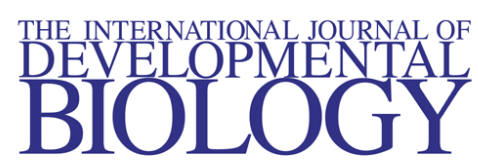

Volume 48 Nos. $5 / 6$ Special issue

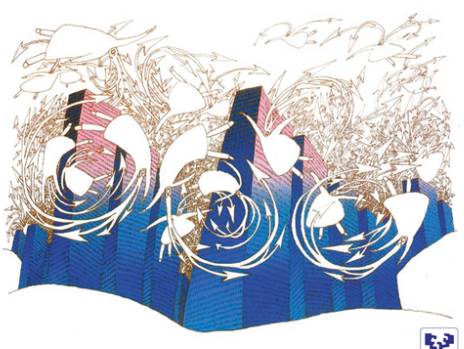

Invasion in cancer and embryonic development 